\title{
Mental Health and Distress as a Social Justice Issue: Guest Editors' Preface and Acknowledgments
}

\author{
LACEY CROFT \\ York University, Canada \\ MANDI GRAY \\ York University, Canada \\ HEIDI RIMKE \\ University of Winnipeg, Canada
}

When we conceived this project in January 2015, we decided to focus on pulling together critical research to examine, document, and problematize the pathological approach to human being by interrogating the increasing psychiatrization of human life and social problems. The biomedical or "psychocentric" approach has proliferated throughout society and can be seen in popular cultural expressions, organizational cultures, and academic discourse alike. The hegemony operates on different levels and through multiple mechanisms that blame the individual and thus erase the social context and social bases of many individualized problems in neoliberal society. Thus, in neoliberal culture, the forces of pathological individualism proliferate while social structural factors at play in mental, emotional, physical and social lives are expunged or downplayed. Implicit in our approach is the view that the struggle for mental health justice is a significant yet still largely unaddressed and unrecognized public health concern. It is our hope that this special issue will initiate a larger discussion about the mental and emotional problems and needs in our communities as a basic human right. It is in this vein that these essays seek to provide critical poststructuralist frameworks that interrogate the assumptions and certainties embedded in our extremely psychocentric cultural attitudes, beliefs, desires, and practices concerning the normal and the pathological.

Our objective is to examine mental and emotional health and distress/difference as a social justice issue by examining the ways in which 
the dominant biomedical approaches emphasize individualized flaws or deficits understood here as psychocentrism. Psychocentrism refers to the dominant Western view that pathologies are intrinsic to the person, promoting an individualistic perspective at the expense of social, political, economic, historical and cultural forces that shape human experience. In the early $21^{\text {st }}$ century, the psy complex and industry continue to roll out powerful forms of victim-blaming, double standards, and stigmatization due to being categorized as "mentally ill" - and therefore a delegitimated subject. This set of articles thus shifts focus and analysis from individual to social explanations, and examines the different ways in which psychocentricity operates. Each analysis seeks to analyze the social relations, social structure, social systems, social practices, social organization, and so forth, as inextricably intertwined with human struggle, suffering and pain - or mental and emotional distress.

Drawing on the concept of psychocentrism, this special issue will problematize and critique the increasing pathologization of human life. We argue that the proliferation of psychocentrism should be understood within a broader social, economic, historical and political framework of neoliberalism that hyper-responsibilizes the modern individual as the source of their own suffering (and redemption) as social provisions are increasingly reduced. Psy discourses are so taken-for-granted today that it has become compulsory to think of one's self or others as normal or abnormal, sick, or disordered in some way. The question of mental and emotional health/distress/difference will be examined within critical theoretical frameworks that seek to interrogate the medical and psychiatric models promoted by the human sciences broadly conceived.

Papers chosen to be included in this special issue explore how the growth of psychocentrism has formed a basic cornerstone of contemporary Western society, seen in the colonization and domination of the culture of therapy. The objective of this issue is thus to examine mental health and distress as a social justice issue by examining social rather than individual deficits that underlie human difficulties. The articles and artistic representations in this issue thus shift the focus and analysis from pathological individualism to critical social analysis. The papers utilize critical conceptual frameworks derived from poststructuralism, as well as feminist, anti-capitalist, anticolonial, mad studies, and critical race theory.

When we sent out our Call for Papers for the special issue on Mental Health and Distress as a Social Justice Issue last winter, we were pleasantly surprised and also unprepared for the overwhelming response, having received 46 submissions from 63 scholars and practitioners representing 35 universities in 13 countries from around the world. Clearly, we had touched upon an urgent international matter that demanded and deserved closer attention and analysis. Given the unexpectedly high volume of submissions, in the end we were forced to make difficult choices, restricting final acceptance to six articles that directly applied the concept of psychocentrism 
to problematize the taken-for-granted, biomedical paradigm of mental illness to study mental and emotional distress as a significant, and often overlooked, social justice issue.

We have structured and organized the special issue for a wide audience, including academics, students, practitioners, researchers, survivors, users, community organizations, clinicians, policy analysts, counsellors and anyone else interested in matters relating to issues of mental health and distress in contemporary society.

We would like to acknowledge and thank the many colleagues who took the time to write and send proposals, as well as the talented, hard working, dedicated authors and artists whose contributions are included here. Also, as is usually the case, the special issue would not have been possible without the indispensable work of the many reviewers who so generously provided expert evaluations of the manuscripts. In no small measure, their time, expertise, and collective labour helped to improve the quality of manuscripts singularly and as a whole. We are grateful.

Also, we would like to thank the many artists who submitted work to be considered for inclusion in this special issue. In particular, we would like to thank the following artists for sharing their critical and provocative artwork using different kinds of media. We chose Michelle Barron's "Of Brass and Twine" for the cover image as it speaks directly to the chasm between mental and emotional distress/differences and the lack of adequate social and economic resources, support, and options for many of those struggling with mental and emotional pain. Other creative interventions that we chose to include are: Eleanor Martin's poem, "What She Would Have Wanted;" two images from Alexis Kinloch's, "Anatomical Atlas;" artwork by Hana Shafi, entitled "Anxiety - Don't Think;" and, Bryony Kimmings' and Tim Grayburn's, "Fake It "Til You Make It" excerpt of a play script.

We would also like to thank David Butz, the Editor-in Chief of Studies in Social Justice, for his kind-hearted support, for sharing his expert editorial talents, and for providing otherwise helpful guidance as we worked on crafting this special issue over the last 18 months.

Lacey Croft and Mandi Gray would like to thank Lorna Weir and Alison Howell for encouraging this project, and Heidi Rimke for her ongoing mentorship while working on the special issue.

Heidi Rimke would like to thank Mandi Gray and Lacey Croft for their enthusiastic initiation of this project and for their endurance in seeing it through to the end, which took much longer than we anticipated.

We hope that this special issue of Studies in Social Justice in some way helps those who struggle with mental and emotional distress and difference as an ignored social justice issue, and that it will shine a new light on an old set of social, political, historical and economic problems. 